\title{
Impact of a school-based food garden on attitudes and identification skills regarding vegetables and fruit: a 12-month intervention trial
}

\author{
Shawn Somerset* and Katherine Markwell \\ School of Public Health and Heart Foundation Research Centre, Griffith University, University Drive, \\ Meadowbrook, Queensland 4131, Australia
}

Submitted 26 June 2007: Accepted 19 May 2008: First published online 23 July 2008

\begin{abstract}
Objective: To determine changes in ability to identify specific vegetables and fruits, and attitudes towards vegetables and fruit, associated with the introduction of a school-based food garden.

Design: A 12-month intervention trial using a historical control (control $n$ 132, intervention $n 120$ ), class-based, self-administered questionnaires requiring oneword answers and 3-point Likert scale responses.

Setting: A state primary school (grades 4 to 7 ) in a low socio-economic area of Brisbane, Australia.

Intervention: The introduction of a school-based food garden, including the funding of a teacher coordinator for $11 \mathrm{~h} /$ week to facilitate integration of garden activities into the curriculum.

Main outcome measures: Ability to identify a series of vegetables and fruits, attitudes towards vegetables and fruit.

Analysis: Frequency distributions for each item were generated and $\chi^{2}$ analyses were used to determine statistical significance. Exploratory factor analysis was employed to detect major trends in data.

Results: The intervention led to enhanced ability to identify individual vegetables and fruits, greater attention to origins of produce (garden-grown and fresh), changes to perceived consumption of vegetables and fruits, and enhanced confidence in preparing fruit and vegetable snacks, but decreased interest in trying new fruits. Conclusions: The introduction of this school-based food garden was associated with skill and attitudinal changes conducive to enhancing vegetable and fruit consumption. The ways in which such changes might impact on dietary behaviours and intake require further analysis.
\end{abstract}

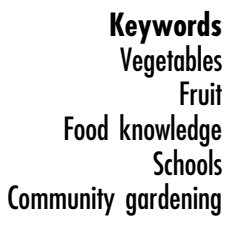

There is clear evidence that inadequate vegetable and fruit intake is associated with higher risk of a range of chronic diseases, including CHD, obesity and some forms of cancer $^{(1)}$. Converting such awareness of into practice presents a major public health challenge, since mean consumption rates for vegetables and fruits across all age groups in many countries are inferior to current recommendations, and in decline ${ }^{(2-4)}$. It is well established that early intervention is an integral step in the prevention of such diseases ${ }^{(5)}$, with major international initiatives focusing on enhancing vegetable and fruit intake in children ${ }^{(6)}$. Recent attention has focused on how the seemingly diverse conceptual frameworks of planned behaviour and ecological influences converge to affect food choice ${ }^{(7)}$. Decisions that determine food choice, including those pertaining to vegetable and fruit consumption, precipitate from a complex range of factors related to the knowledge, beliefs, attitudes, skills, preferences of and access by individuals. Issues such as taste, convenience, cost and health concerns have been identified as significant influences on dietary intake in adults, adolescents and children ${ }^{(8,9)}$, although the relative importance of each is less apparent ${ }^{(7)}$. Notwithstanding this, solutions to enhance vegetable and fruit intake are often tailored to specific settings, demographics ${ }^{(6,10,11)}$, health issues $^{(12)}$ and technologies ${ }^{(13,14)}$.

Determinant factors of an individual's vegetable and fruit intake do not operate in isolation, but are expressed in the context of external physical and social environments ${ }^{(2)}$. For example, television viewing and its associated exposure to junk food advertising compromises the intake of more wholesome foods such as fresh vegetables and fruit ${ }^{(14,15)}$. The exact relationship between television viewing and fruit and vegetable intake is unclear, but sustainable solutions involve more than 
simply denying individuals access to television. The socio-cultural environment centred largely on passive interaction with 'virtual' peers (e.g. television, Internet, etc.) requires innovations in health promotion that influence factors determining individual choice and the broader public nutrition environment. Community-centred foodbased interventions such as collective kitchens ${ }^{(16)}$ and community gardens ${ }^{(17)}$ provide examples of potential directions for innovation.

There is compelling evidence that vegetable and fruit consumption is driven by knowledge of and attitudes towards such foods, and that instituting changes to these factors in children can influence subsequent consumption $^{(18)}$. This relationship is also implied in many schoolbased interventions to influence awareness by exposure to a wider range of vegetables and fruits ${ }^{(10)}$, self-efficacy and availability $^{(2)}$ to enhance vegetable and fruit consumption. There is growing evidence that community gardening has the potential to positively influence dietary intake, as well as physical activity and socially productive activity ${ }^{(19,20)}$.

Recent evidence supports the potential for school-based food gardens as a useful nutrition education tool, and general agreement exists that gardens can be a beneficial addition to school resources ${ }^{(19)}$. Evidence of a more empirical nature is emerging which supports this general premise, identifying their potential for affecting dietary behaviour change. McAleese and Rankin ${ }^{(21)}$ have demonstrated recently that integration of school garden activities into a short-term nutrition education programme can enhance self-reported vegetable and fruit consumption in children aged 10 to 13 years. In an expanded age range of 8 to 15 years, Lautenschlager and Smith ${ }^{(22)}$ showed that a 10-week garden programme (which incorporated a nutrition curriculum) enhanced vegetable and fruit intake, at least in boys. In a longer (6-month) intervention, school gardens were reported to enhance nutrition knowledge and skills in Indigenous schools in a remote region of Australia $^{(23)}$. Nutrition knowledge also improved after a 6-month combined nutrition and garden intervention in US fourth-grade students ${ }^{(24)}$. That study also showed enhanced preferences for certain vegetables post-intervention. After-school gardening can have a positive impact on self-reported vegetable intake and physical activity ${ }^{(25)}$.

The present intervention study was initiated to determine if the installation of a garden within a primary school could influence children's ability to identify specific vegetables and fruits, and attitudes that may affect long-term vegetable and fruit consumption.

\section{Methods}

\section{Participants and recruitment}

All students from a single primary (elementary) school in grades 4 to 7 (corresponding approximately to ages 8 to 13 years), in each of two consecutive data collection years, were included in this study. The school was located in a northern Brisbane suburb (eastern Australia), designated as a socio-economically disadvantaged area characterised by high unemployment rates and high Indigenous and migrant populations.

\section{Intervention}

The intervention comprised the funding ( $11 \mathrm{~h} /$ week) of a qualified teacher with extensive experience in the establishment and maintenance of permaculture gardens for a period of 12 months. The garden-based teacher was employed by the project (not by the school) to liaise with teachers of all grades within the school, to facilitate the incorporation of garden activities into their curricula (rather than conduct teaching sessions, although this did occur from time to time).

The garden-based teacher had overall responsibility for the maintenance of the garden. This teacher was also responsible for the scheduling of class access to the garden, coordinating weekly activities in the garden, promotion of the garden throughout the school, conducting sessions on specialised aspects of garden maintenance for classes (e.g. composting, propagation, planting, harvesting, cooking), and identification and development of garden-related curriculum resources which could be used by teachers.

The garden was established near the edge of the school boundary to facilitate involvement of the local community in garden maintenance activities. Over the course of the intervention, the garden plot developed into a site approximately $20 \mathrm{~m} \times 20 \mathrm{~m}$ in size. One corner of this block was set up as an outdoor classroom. Facilities such as garden beds, composting bays, a garden pond and a greenhouse were located on the plot. Over the course of the year, all classes within the school engaged in weekly activities centred round the garden. Classes across the school shared responsibilities for planting, tending and harvesting in the garden. Experience varied, but specific examples of interaction are consistent with those previously reported for school gardens ${ }^{(20)}$. The garden also became a focal point for whole-of-school activities such as fund-raising, media promotion and meal sharing occasions. A list of activities with which students were engaged emerged from an independent process evaluation, as outlined in Table 1.

From a process perspective, a number of factors were integral to the successful development of the current intervention. Effective relationship building with the school's principal and key teachers was important to facilitate engagement by the school community. The conduct of baseline data collection within the school formed an important part of communication about the project, and consequent relationship building. A part-time coordinator with education training was a useful conduit between the garden and curricular activities. This also enabled teachers to use the garden for teaching without the 
Table 1 Garden-related activities with which students engaged during the course of the school year, as determined by a separate process evaluation: 12-month intervention trial of a school-based food garden, Brisbane, Australia. Classification framework adapted from Anderson et al. ${ }^{(6)}$

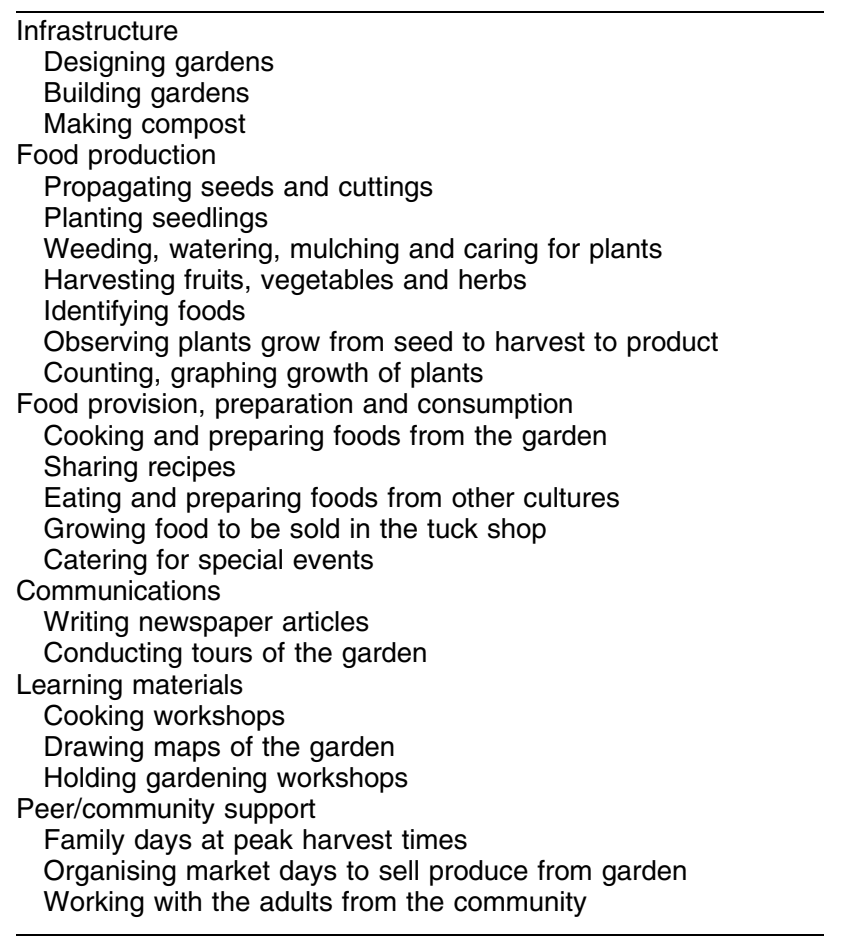

burden of garden maintenance. Relationships with a local adult permaculture education facility (landscape design), a community garden (horticultural expertise) and a PoliceCitizens Youth Club (security) were seen as particularly important for the development and consolidation of the garden.

\section{Instruments}

Two questionnaires were developed specifically for evaluation of the project. The attitudes questionnaire was based largely on the format of a survey tool previously validated and used by Miller and co-workers in Australian primaryschool children ${ }^{(11,26)}$. The questionnaire involved a series of thirty-eight items (see Table 2) to which responses via a 3-point Likert scale were required. A vegetable and fruit identification survey, requiring a one-word answer, also was developed to test the ability to identity the following thirty-one foods: broccoli, capsicum, potato, cucumber, tomato, aubergine, pumpkin, mushroom, chilli, shallot, garlic, onion, beetroot, radish, sweet corn, carrot, courgette, avocado, strawberry, banana, grape, apple, orange, coconut, starfruit, nectarine, pineapple, cherry, mandarin, watermelon and kiwifruit. The surveys were evaluated by a trained primary-school teacher for content validity, then pilot-tested in a group of six children aged 8 years to determine the appropriateness of the questions for this age group and modified accordingly. A test-retest assessment of reliability of the questionnaire ( 1 week apart) using $\chi^{2}$ analysis in
Table 2 Determinant questionnaire items and associated constructs: 12-month intervention trial of a school-based food garden, Brisbane, Australia. Response categories comprised a 3-point scale ('yes', 'sort of' and 'no'). Numbers in square brackets indicate the grade in which significant differences occurred between control and intervention groups. Items and constructs adapted from De Bourdeaudhuij et al. ${ }^{(27)}$

Personal

Attitude

Do you think fruit is dull and boring?

When you're worried, do you like to eat fruit?

When you're sad, does fruit makes you happy? [4]

After you eat fruit do you still feel hungry? [5]

Do you think vegetables are fun and exciting?

Self-efficacy

Do you help prepare or cook fruit or vegetables for meals (like cut-up veggies)?

Do you eat lots of fruit?

Do you eat lots of vegetables? [6]

Are you good at making fruit or vegetable snacks (like carrot sticks, fruit salad)? [6]

Do you eat some fruit most days? [4]

Liking (vegetables and fruits)

Do you think most vegetables taste good?

Do you think most fruit tastes bad? [7]

Do you like fruit and vegetable snacks?

Do you like to eat vegetables every day?

Do you like lots of different coloured vegetables in your meals?

Do you hate cooked vegetables?

Do you like raw vegetables (for example, salad)?

Liking (general)

Do you like salty food?

Do you like sweet food?

Preferences

Do you think vegetables from the garden taste better than from the shop? $[4,6]$

Do you prefer to eat fruit when you're really hungry? $[4,5]$

Do you like fruit bars/roll ups better than fresh fruit?

Do you like dried fruit better than fresh fruit?

Do you like tinned fruit more than fresh fruit? [6]

Perceived barriers

Do you like trying new fruit? $[4,5]$

Do you like trying new vegetables?

Knowledge

Do you think eating fruit and vegetables every day keeps you healthy?

Would you like to learn more about fruit and vegetables at school? [5]

Would you like to learn how to be healthy at school? $[4,6]$

Perceived social environment (modelling)

Do most of your friends like fruit as a snack? [6, 7]

Does your family eat lots of vegetables? [4]

Do your friends eat lots of fruit?

Do your friends eat lots of vegetables? [6]

Does your family eat lots of fruit?

Do most of your friends like raw vegetables as snacks?

Perceived physical environment

Do you like eating fruit or vegetable snacks that someone has made for you?

Are there a lot of fruit and vegetables at home?

Do you grow fruit and vegetables at home in the garden? $[5,6]$

a sub-sample ( $n$ 20) of the control group showed no difference in responses $(P<0 \cdot 05)$.

\section{Procedure}

A historical control design ${ }^{(28)}$ was employed, where students completed questionnaires in early autumn of the first data collection year, within 1 month prior to the start of the intervention. These data were used as a control for 


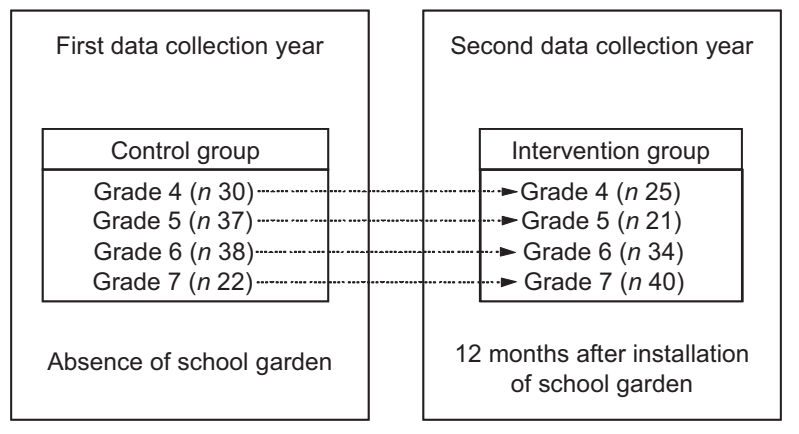

Fig. 1 Summary of experimental (historical control) design used in the present study. Arrows indicate the comparisons made in $\chi^{2}$ analysis

subsequent data collection, in early autumn of the second data collection year (approximately one year after the introduction of the garden to the school). Thus, data from grades 4, 5, 6 and 7 in the school year just prior to the intervention (i.e. introduction of the garden) were used as control for grades 4, 5, 6 and 7 during the school year which experienced the intervention. The data collection design is summarised in Fig. 1.

Data collection was conducted as a series of class exercises by the teacher of each class, with each teacher supervising completion of questionnaires. Teachers were given a standard instruction sheet on administering each of the survey tools. Data were collected from all grade 4 to 7 students within the school for both the control ( $n$ 132) and intervention ( $n$ 120) groups, as outlined above. Information explaining the nature of the study was forwarded to all parents/guardians of the students. An opportunity was given to all parents/guardians to request further information and, if desired, opt out of the data analysis phase. Similarly, all students were given the same opportunity. No incentives were provided for participation. All procedures were reviewed and approved by the Human Research Ethics Committee of Griffith University.

\section{Data analysis}

Survey data were analysed using the Statistical Package for the Social Sciences statistical software package version $12 \cdot 0$ (SPSS Inc., Chicago, IL, USA). In the intervention group, responses from two students in grade 7 who had been attending the school for less than 6 months were excluded from the analysis. Frequency distributions for each item were generated and $\chi^{2}$ analyses were used to determine the statistical significance of differences between the control and intervention groups (which were treated as independent samples for the purposes of statistical analysis).

\section{Results}

The control group (data collection year 1) comprised thirty, thirty-seven, thirty-eight and twenty-two subjects, and the intervention group (data collection year 2) comprised twenty-five, twenty-one, thirty-four and forty subjects in grades 4, 5, 6 and 7, respectively. Grades 4 to 7 represented approximately $60 \%$ of the total school population (comprising grades 1 to 7 ) in each data collection year. There were no significant differences in gender distributions between the control and intervention groups $(P<0 \cdot 05)$.

\section{Awareness: ability to identify specific vegetables and fruits}

There were significant improvements following the intervention in recognition of the following vegetables and fruit by children: capsicum $(P<0 \cdot 05)$, potato $(P<0 \cdot 05)$, cucumber $(P<0 \cdot 001)$, aubergine $(P<0 \cdot 001)$, chilli $(P<0 \cdot 001)$, shallot $(P<0 \cdot 001)$, garlic $(P<0 \cdot 001)$, onion $(P<0 \cdot 001)$, beetroot $(P=0 \cdot 05)$, radish $(P<0 \cdot 001)$, courgette $(P<0 \cdot 001)$, avocado $(P=0.05)$, grape $(P<0.05)$, coconut $(P<0 \cdot 001)$, starfruit $(P<0 \cdot 001)$, peach $(P<0 \cdot 05)$, cherry $(P<0 \cdot 001)$, mandarin $(P<0 \cdot 001)$, watermelon $(P<0 \cdot 001)$ and kiwifruit $(P<0 \cdot 001)$.

\section{Determinant questionnaire}

Items to which statistically significant differences between control and intervention responses were observed are outlined in Table 3. The major trends for each of these changes are also noted in Table 3. The significant changes according to recognised determinants (constructs) of vegetable and fruit consumption are noted in Table 2. Exploratory factor analysis of control data yielded no significant results for any of the individual school years, and was not pursued further.

There was a shift towards more children from grade 7 rating fruit as tasting bad $(P<0 \cdot 05)$. Although not statistically significant, fewer students responded 'no' to the question 'Do vegetables taste bad?' More children in grades 4, 5 and 6 appeared to feel vegetables tasted good following the intervention (36\% to $74 \%$, $64 \%$ to $68 \%$, and $30 \%$ to $42 \%$, respectively). Grade 7 responses decreased from $36 \%$ to $31 \%$.

More children also said they liked to eat vegetables every day in grades 4,5 and 6 , from $33 \%$ to $50 \%, 47 \%$ to $65 \%$ and $26 \%$ to $35 \%$, respectively. Grade 7 decreased from $23 \%$ to $18 \%$ in 'yes' responses, but also decreased in 'no' responses from $46 \%$ to $35 \%$. The majority of responses were 'sort of' (47\%) following the intervention.

Grades 5 and 6 scored slightly higher post-intervention for answering affirmatively that they would like to taste fruit and vegetables in class (67\% to $76 \%$ and $45 \%$ to $47 \%$, respectively). Grades 4 and 7 decreased (70\% to $59 \%$ and $55 \%$ to $41 \%$, respectively) post-intervention.

There was some evidence of discernment in the term 'freshness' post-intervention, with more children in grade 6 preferring fresh fruit to tinned fruit $(P<0 \cdot 01)$. In terms of preferences specifically towards vegetables, following the intervention students in grades 4 and 6 thought 
Table 3 Patterns of changes of responses to items between control and intervention groups, according to grade: 12-month intervention trial of a school-based food garden, Brisbane, Australia

\begin{tabular}{|c|c|c|c|c|}
\hline Item & Major trends in change & $\chi^{2}$ & $P$ & $\begin{array}{l}\text { Grades which } \\
\text { showed change }\end{array}$ \\
\hline \multicolumn{5}{|l|}{ Grade 4} \\
\hline Do you eat some fruit most days? & $\downarrow$ yes, $\uparrow$ no & $17 \cdot 695$ & 0.000 & 4 \\
\hline When you're sad, does fruit makes you happy? & $\downarrow$ yes, $\uparrow$ sort of, $\downarrow$ no & $6 \cdot 916$ & 0.032 & 4 \\
\hline Do you hate cooked vegetables? & $\uparrow$ sort of, $\downarrow$ no & $11 \cdot 346$ & 0.003 & 4 \\
\hline Does your family eat lots of vegetables? & $\downarrow$ yes, $\uparrow$ no & $11 \cdot 934$ & 0.003 & 4 \\
\hline Do you like trying new fruit? & $\downarrow$ yes, $\uparrow$ no & $11 \cdot 441$ & 0.003 & 4,5 \\
\hline Do you prefer to eat fruit when you're really hungry? & $\downarrow$ yes, $\uparrow$ no & $9 \cdot 739$ & 0.008 & 4,5 \\
\hline $\begin{array}{l}\text { Do you think vegetables from the garden taste better than } \\
\text { from the shop? }\end{array}$ & $\uparrow$ yes, $\downarrow$ no & $8 \cdot 783$ & $0 \cdot 012$ & 4,6 \\
\hline Would you like to learn how to be healthy at school? & $\downarrow$ yes, $\uparrow$ sort of & $14 \cdot 089$ & 0.001 & 4,6 \\
\hline \multicolumn{5}{|l|}{ Grade 5} \\
\hline Do you like trying new fruit? & $\downarrow$ yes & $10 \cdot 875$ & 0.004 & 4,5 \\
\hline Do you prefer to eat fruit when you're really hungry? & $\downarrow$ yes & $13 \cdot 158$ & 0.001 & 4,5 \\
\hline After eating fruit do you still feel hungry? & yes & $7 \cdot 967$ & 0.019 & 5 \\
\hline Would you like to learn more about fruit and vegetables at school? & $\downarrow$ yes, $\uparrow$ sort of & $7 \cdot 217$ & 0.027 & 5 \\
\hline Do you grow fruit and vegetables at home in the garden? & $\uparrow$ sort of, $\downarrow$ no & $9 \cdot 136$ & 0.010 & 5,6 \\
\hline \multicolumn{5}{|l|}{ Grade 6} \\
\hline $\begin{array}{l}\text { Do you think vegetables from the garden taste better than from } \\
\text { the shop? }\end{array}$ & $\uparrow$ yes, $\downarrow$ no & $14 \cdot 366$ & $0 \cdot 001$ & 4,6 \\
\hline Would you like to learn how to be healthy at school? & $\downarrow$ yes, $\uparrow$ sort of, $\downarrow$ no & $14 \cdot 089$ & 0.001 & 4,6 \\
\hline Do you grow fruit and vegetables at home in the garden? & $\downarrow$ no & $10 \cdot 119$ & 0.006 & 5,6 \\
\hline $\begin{array}{l}\text { Are you good at making fruit or vegetable snacks (like carrot } \\
\text { sticks, fruit salad)? }\end{array}$ & $\downarrow$ yes, $\uparrow$ sort of & $8 \cdot 312$ & $0 \cdot 016$ & 6 \\
\hline Do your friends eat lots of vegetables? & $\uparrow$ yes, $\uparrow$ sort of, $\downarrow$ no & $11 \cdot 441$ & 0.003 & 6 \\
\hline Do you eat lots of vegetables? & $\uparrow$ yes, $\downarrow$ no & $7 \cdot 736$ & 0.021 & 6 \\
\hline Do you like tinned more than fresh fruit? & $\downarrow$ yes, $\uparrow$ sort of & $9 \cdot 372$ & 0.009 & 6 \\
\hline Do most of your friends like fruit as a snack? & $\uparrow$ sort of, $\downarrow$ no & $8 \cdot 767$ & 0.012 & 6,7 \\
\hline \multicolumn{5}{|l|}{ Grade 7} \\
\hline Do most of your friends like fruit as a snack? & $\uparrow$ sort of, $\downarrow$ no & $9 \cdot 932$ & 0.007 & 6,7 \\
\hline Do you think most fruit tastes bad? & $\uparrow$ yes, $\uparrow$ sort of & $6 \cdot 856$ & 0.032 & 7 \\
\hline
\end{tabular}

Table 4 Responses to the question 'Do you think vegetables from the garden taste better than from the shop?' according to grade: 12-month intervention trial of a school-based food garden, Brisbane, Australia

\begin{tabular}{llccc}
\hline Grade & Response & Control & Intervention & Total \\
\hline 4 & Yes & 8 & 12 & 20 \\
& Sort of & 5 & 8 & 13 \\
& No & 10 & 1 & 11 \\
& Total & 23 & 21 & 44 \\
5 & Yes & 18 & 15 & 33 \\
& Sort of & 4 & 5 & 9 \\
& No & 8 & 0 & 8 \\
& Total & 30 & 20 & 50 \\
6 & Yes & 10 & 19 & 29 \\
& Sort of & 2 & 10 & 12 \\
& No & 17 & 5 & 22 \\
& Total & 29 & 34 & 63 \\
7 & Yes & 7 & 6 & 13 \\
& Sort of & 5 & 13 & 18 \\
& No & 6 & 15 & 21 \\
& Total & 18 & 34 & 52 \\
\hline & & & & \\
& & &
\end{tabular}

vegetables from the garden tasted better than from the shop $(P<0 \cdot 05)$, although changes in the proportions of responses varied according to grade (see Table 4). Despite more children in grade 4 feeling vegetables tasted good following the intervention, there was a shift towards more children reporting they hated cooked vegetables $(P<0 \cdot 01)$. For hating cooked vegetables, grades 5 and 6 had a large amount of respondents agreeing with the question following the intervention, with $40 \%$ and $38 \%$, respectively. Grade 7 maintained its response rate of $28 \%$ responding 'yes' to this question.

There was an increase in respondents answering 'yes' when asked if their friends ate lots of vegetables after the intervention. Grade 6 increased from $11 \%$ to $32 \%$ $(P<0 \cdot 01)$, grade 5 from $24 \%$ to $70 \%$, and grade 7 from $19 \%$ to $23 \%$.

\section{Discussion}

There was a clear improvement in the ability of students of all ages to identify specific vegetables and fruits associated with the current intervention. This ability is only one means by which food awareness can be expressed. However, these results raise the possibility that other aspects of food awareness may also be affected through garden-based activities. This may potentially contribute to enhancing accessibility of children to vegetables and fruits, which is an important determinant of consumption by children in this age group ${ }^{(29)}$. However, the relationship between knowledge and consumption is complex, with knowledge about intake recommendations being associated with increased intake ${ }^{(29)}$ but nutrition knowledge alone being only weakly associated with dietary behaviour $^{(30)}$. 
A major effect associated with the presence of the garden in the study school was the attribution of added value towards vegetables and fruits that are 'gardengrown', an effect that was observed in grades 4 to 6 . Previous evidence suggests that the application of biography and geography to food can contribute to augmentation of the consumption of such foods ${ }^{(31)}$. There is also evidence that some degree of closer personal involvement in the production and preparation of food can influence planned behaviour, especially regarding foods that are often difficult to change behaviour towards ${ }^{(32,33)}$. These changes in attitude to garden-grown vegetables were observed in conjunction with a substantial increase in the ability of children to identify specific vegetables and fruits.

The garden-based teacher in the present study was blinded to the evaluation tool, implying that this skill developed as a general consequence of enhanced awareness of vegetables and fruits resulting from contact with the garden. Cockroft et $a l^{(10)}$ have proposed that increasing awareness is a viable strategy for enhanced consumption of vegetables and fruits. The significant increase in appreciation for garden-grown ( $v$. storebought) and fresh ( $v$. tinned; as noted for grade 6 students) may represent a theme for further development in future interventions of this type. The notion of gardengrown seemed to have expanded with age to a broader view of 'freshness' $v$. processed or 'tinned'.

In grades 6 and 7 , an awareness of peer preferences and consumption emerged (i.e. perceived social environment), whereas changes in grades 4 and 5 were more centred on individual (first-person) considerations. Self-efficacy in terms of ability to prepare vegetables and fruits, and changes in awareness of personal (first-person) consumption of vegetables, also were apparent in grade 6 responses. The present data showed more extensive change in responses about perceived intake than about attention to health-related issues by students. An interesting reluctance to learn more about vegetables and fruits, and how to be healthy, emerged across grades 4, 5 and 6 .

There was a substantial variation in effects on responses between age groups (see Table 3). Of particular note was the lower number of significant changes in responses to questions by grade 7 students. This difference may in part be explained by the autonomy in food choice and other behaviour expanding as children grow up ${ }^{(7)}$. This may also be a factor in the observation that changes noted in grades 4 and 5 were much more focused on personal (first-person) perspectives, compared with awareness of their social environment. Longitudinal ${ }^{(3)}$ and secular ${ }^{(34)}$ declines in vegetable and fruit consumption according to age have been reported previously. The utility of school gardens to enhance vegetable and fruit consumption may be more effective for use in younger age groups, preparing them for a seemingly inevitable decrease in intake during adolescence.
There was also no apparent consistency in responses to items regarding fruit $v$. vegetables. Reinaerts et al. have proposed that the mechanisms driving vegetable and fruit consumption are quite different, based on their observation that fruit consumption is affected far more by habit and availability than is vegetable consumption ${ }^{(7)}$. This challenges some quite fundamental concepts in nutrition promotion, such as including vegetables and fruits in the same food group for the purposes of dietary advice and promotion.

There was some dissonance in the effects associated with the present intervention which require further analysis. The move away from children in grade 7 answering 'no' to fruit as tasting bad towards 'sort of' is difficult to interpret without further information. It may reflect a consolidation of views; whereas before they were unsure of preferences, after regular exposure to the garden they may be more certain of their dislikes. This is clearly an issue which warrants further investigation, since neophobia is an important barrier to adequate vegetable and fruit consumption ${ }^{(35)}$. Further, there was less enthusiasm for activities centred around vegetables and fruits after this intervention, with a general move from the 'yes' response to the more ambivalent 'sort of' response. This may have arisen in part because increased exposure to the garden turned what was initially considered by children a novel experience into a mainstream activity. This also may explain the similar trend of a decrease in interest to try new fruits. As with any attitudinal change, it is important to understand the influence of this attitude on dietary behaviour and intake.

Perceptions of consumption showed a complex mix of trends. More children in grade 4 reported eating fruit most days and more grade 6 students indicated that they ate 'lots of vegetables'. However, there was a decrease in the proportion of children in grade 4 reporting that their family ate a lot of fruit. This may reflect a higher degree of contemplation about the vegetable and fruit intake of family members in response to garden-centred activities. There is some evidence that parental vegetable and fruit intake is a strong predictor of intake for their children ${ }^{(35)}$, but although perceptions of availability of these foods have been reported for this age group ${ }^{(36)}$, the significance of these beliefs is not well understood.

An important issue in the interpretation of the present trial is defining the nature of the intervention. We have taken the position similar to an 'intention to treat' trial ${ }^{(29)}$, in that resources and assistance for the establishment and maintenance of the garden were provided, but beyond this no specific instructions about how the garden might be integrated into school activities were prescribed. In fact, the nature of the intervention emerged prospectively through an independent process evaluation of the project. An important limitation of this approach is that the apparent complexity of the intervention makes it difficult to pinpoint the specific key factor(s) which generated the observed effects. 
In addition to the difficulty in defining the precise nature of the intervention, some other limitations of the present study are worth noting. The study was restricted to relatively small numbers of students in a single school, which limits generalisability of the results. Immediate dietary intake data (in the form of $24 \mathrm{~h}$ recall) are not included in the present analysis. McAleese and Rankin ${ }^{(21)}$ have previously pointed out the weaknesses inherent in using such data to predict long-term dietary behaviour, in a study which used three consecutive $24 \mathrm{~h}$ recalls to collect data. Lautenschlager and Smith ${ }^{(22)}$ relied on a single $24 \mathrm{~h}$ recall for data collection, further weakening relevance to long-term consumption. The range of important psychosocial determinants of long-term vegetable and fruit intake outlined by Reinaerts et al. ${ }^{(7)}$ provides a framework for the emphasis on such determinants in the present study. The often ambiguous relationships between changes in upstream determinant factors, downstream dietary behaviours and, ultimately, health outcomes are not unique to the present study and pose significant challenges to public nutrition research in general.

The use of a historical control, rather than a control group from another school, presented some advantages for the present community-based intervention study. The ideal control in this type of intervention trial would have been a school with identical sociodemographic characteristics, the only difference being the presence of a food garden. In essence, the use of a historical control enabled such control, in contrast to the non-equivalent control groups design used by McAleese and Rankin ${ }^{(21)}$, where such characteristics could not be controlled for. This mechanism also avoids issues associated with the quality of participation of a control school, which would likely have been inferior to a school which was receiving the benefits of the installation of an education facility such as a garden, thus affecting the quality of data collected.

Effective use of a historical control design depends on minimal temporal shifts in factors affecting outcomes of interest across the general population over the study period $^{(28)}$. The relative absence of coordinated national and regional promotion of vegetable and fruit consumption in Australia during the period of data collection would have contributed to the experimental stability required for this study design.

The present study showed that the introduction of a vegetable garden within a school can enhance a range of personal determinant factors of vegetable and fruit consumption, as well as perceived social and physical environments. These findings support the inclusion of school gardens as a useful component of experiential learning strategies for nutrition education. A better understanding of the observed effects according to factors such as socio-economic status and dietary intake would enhance the utility of school garden-related activity in targeting those at highest risk of poor nutrition. Since many schools do not have appropriate resources for the establishment of food gardens, identification and evaluation of other settings conducive to experiential learning about food and nutrition are warranted.

\section{Acknowledgements}

The contributions of Northey Street City Farm workers and Education Queensland staff are gratefully acknowledged. This school garden project was supported in part by a grant from Health Promotion Queensland. We are aware of no conflict of interest. S.S. designed and implemented the study, collected the data and wrote the first draft of the paper. K.M. worked on statistical analysis of the data. Both authors provided critical revision of the paper, and read and approved the final manuscript.

\section{References}

1. Block G, Patterson B \& Subar A (1992) Fruit, vegetables and cancer prevention: a review of epidemiologic evidence. Nutr Cancer 18, 1-29.

2. Kristjansdottir AG, Thorsdottir I, De Bourdeaudhuij I, Due P, Wind M \& Klepp K-I (2006) Determinants of fruit and vegetable intake among 11-year-old schoolchildren in a country of traditionally low fruit and vegetable consumption. Int J Behav Nutr Phys Act 3, 41.

3. Larson NI, Neumark-Sztainer D, Hannan PJ \& Story M (2007) Trends in adolescent fruit and vegetable consumption, 1999-2004. Am J Prev Med 32, 147-150.

4. Vereecken K \& Maes L (2000) Eating habits, dental care and dieting. In Health Policy for Children and Adolescents. WHO Policy Series no. 1, pp. 83-96. Geneva: WHO.

5. Caballero B (2001) Early nutrition and risk of disease in the adult. Public Health Nutr 4, 1335-1336.

6. Anderson AS, Porteous LEG, Foster E, Higgins C, Stead M, Hetherington M, Ha MA \& Adamson AJ (2005) The impact of a school-based nutrition education intervention on dietary intake and cognitive and attitudinal variables relating to fruits and vegetables. Public Health Nutr 8, 650-656.

7. Reinaerts E, de Nooijer J, Candel M \& de Vries N (2007) Explaining school children's fruit and vegetable consumption: the contributions of availability, accessibility, exposure, parental consumption and habit in addition to psychosocial factors. Appetite $\mathbf{4 8}, 248-258$.

8. Glanz K, Basil M, Malback E, Goldberg J \& Snyder D (1998) Why Americans eat what they do: taste, nutrition, cost, convenience and weight control concerns as influences on food consumption. J Am Diet Assoc 98, 1118-1126.

9. O'Dea J (2003) Why do kids eat healthful food? Perceived benefits of and barriers to healthful eating and physical activity among children and adolescents. J Am Diet Assoc 103, 497-501.

10. Cockroft JE, Durkin M, Masding C \& Cade JE (2005) Fruit and vegetable intakes in a sample of pre-school children participating in the 'Five for All' project in Bradford. Public Health Nutr 8, 861-869.

11. Newell S, Huddy A, Adams J, Miller M, Holden L \& Dietrich U (2004) The Tooty Fruity Vegie project: Changing knowledge and attitudes about fruits and vegetables. Aust $N Z J$ Public Health 28, 288-295.

12. Lake AA, Speed C, Brookes A, Heaven B, Adamson AJ, Moynihan P, Corbett S \& McColl E (2007) Development of a series of patient information leaflets for constipation using 
a range of cognitive interview techniques: LIFELAX. BMC Health Serv Res 7, 3.

13. Beaudoin CE, Fernandez C, Wall JL \& Farley TA (2002) Promoting healthy eating and physical activity. Short-term effects of a mass media campaign. Am J Prev Med 32, 217-223.

14. Borzekowski DL \& Robinson T (2001) The 30-second effect: an experiment revealing the impact of television commercials on food preferences of preschoolers. $J$ Am Diet Assoc 101, 42-46.

15. Salmon J, Campbell KJ \& Crawford DA (2006) Television viewing habits associated with obesity risk factors: a survey of Melbourne schoolchildren. Med J Aust 184, 64-67.

16. Fano TJ, Tyminski SM \& Flynn MA (2004) Evaluation of a collective kitchens program: using the Population Health Promotion Model. Can J Diet Pract Res 65, 72-80.

17. Armstrong D (2000) A survey of community gardens in upstate New York: implications for health promotion and community development. Health Place 6, 319-327.

18. Bere E \& Klepp K-I (2005) Changes in accessibility and preferences predict children's future fruit and vegetable intake. Int J Behav Nutr Phys Act 2, 15-23.

19. Graham H, Beall D, Lussier M, McLaughlin P \& ZidenbergCherr S (2005) Use of school gardens in academic instruction. J Nutr Educ Behav 37, 147-151.

20. Somerset S, Ball R, Flett M \& Geissman R (2005) Schoolbased community gardens: re-establishing healthy relationships with food. J Home Econ Inst Aust 12, 25-33.

21. McAleese JD \& Rankin LL (2007) Garden-based nutrition education affects fruit and vegetable consumption in sixth-grade adolescents. J Am Diet Assoc 107, 662-665.

22. Lautenschlager L \& Smith C (2007) Understanding gardening and dietary habits among youth garden program participants using the Theory of Planned Behavior. Appetite 49, 122-130.

23. Viola A (2006) Evaluation of the Outreach School Garden Project: building the capacity of two Indigenous remote school communities to integrate nutrition into the core school curriculum. Health Prom J Aust 17, 233-239.

24. Morris JL \& Zidenberg-Cherr S (2002) Garden-enhanced nutrition curriculum improves fourth-grade school children's knowledge of nutrition and preferences for some vegetables. J Am Diet Assoc 102, 91-93.
25. Hermann JR, Parker SP, Brown BJ, Siewe YJ, Denney BA \& Walker SJ (2006) After-school gardening improves children's reported vegetable intake and physical activity. J Nutr Educ Behav 38, 201-202.

26. Miller M, Newell S, Huddy A, Adams J, Holden L \& Dietrich UD (2001) Tooty Fruity Vegie Project: Process and Impact Evaluation Report. Lismore: Health Promotion Unit, Northern Rivers Area Health Service.

27. De Bourdeaudhuij I, Klepp KI, Due P, Rodrigo CP, de Almeida M, Wind M, Krolner R, Sandvik C \& Brug J (2005) Reliability and validity of a questionnaire to measure personal, social and environmental correlates of fruit and vegetable intake in 10-11-year-old children in five European countries. Public Health Nutr 8, 189-200.

28. Piantadosi S (2005) Clinical Trials. A Methodological Perspective. New Jersey: Wiley Interscience.

29. Heritier S, Gebski V \& Keech A (2003) Inclusion of patients in clinical trial analysis: the intention-to-treat principle. Med J Aust 179, 438-440.

30. Story M, Neumark-Sztainer D \& French S (2002) Individual and environmental influences on adolescent eating behaviors. J Am Diet Assoc 102, S40-S51.

31. Cook I, Crang P \& Thorpe M (1998) Biographies and geographies: consumer understandings of the origins of foods. Br Food J 100, 162-167.

32. Juhl HJ \& Poulsen C (2000) Antecedents and effects of consumer involvement in fish as a product group. Appetite 34, 261-267.

33. Verbeke W \& Vackier I (2005) Individual determinants of fish consumption: application of the theory of planned behaviour. Appetite 44, 67-82.

34. Vereecken CA, Inchley J, Subramanian SV, Hublet A \& Maes L (2005) The relative influence of individual and contextual socio-economic status on consumption of fruit and soft drinks among adolescents in Europe. Eur J Public Health 15, 224-232.

35. Cooke L, Wardle J, Gibson E, Sapochnik M, Sheiham A \& Lawson M (2003) Demographic, familial and trait predictors of fruit and vegetable consumption by pre-school children. Public Health Nutr 7, 295-302.

36. Sandvik C, De Bourdeaudhuij I, Due P et al. (2005) Personal, social and environmental factors regarding fruit and vegetable intake among schoolchildren in nine European countries. Ann Nutr Metab 49, 255-266. 